\title{
How's Your Health at Home: Frail Homebound Patients Reported Health Experience and Outcomes*
}

\author{
Margaret J. McGregor, 1,2,3 Jay Slater, ${ }^{2}$ John Sloan, ${ }^{2}$ Kimberlyn M. McGrail, 1,3,4 \\ Anne Martin-Matthews, ${ }^{5}$ Shannon Berg, ${ }^{1,6}$ Alyson Plecash, ${ }^{2}$ Leila Sloss, ${ }^{2}$ Johanna Trimble, ${ }^{2,7}$ and \\ Janice M. Murphy ${ }^{8}$
}

\begin{abstract}
RÉSUMÉ
Pour notre sondage, nous avons utilisé une méthodologie mixte basée sur le Web (How's Your Health - Frail) pour examiner la santé des adultes fragiles ( $78 \%$ âgés de 80 ans et plus) inscrits à un programme de soins primaires à domicile à Vancouver, au Canada. Soixante pour cent des répondants admissibles ont participé, représentant plus d'un quart (92/350, 26,2\%) de tous les individus qui reçoivent le service. Malgré des niveaux élevés de co-morbidité et de dépendance fonctionnelle, $50 \%$ ont jugé leur santé aussi bonne, très bonne ou excellente. Les ratios de cotes ajustés pour l'auto-évaluation de sa santé positive étaient de 7,50, 95 pour cent d'intervalle de confiance (IC) $[1,09,51,81]$ et $4,85,95 \%$ CI $[1,02,22,95]$ pour l'absence de symptômes gênants et le pouvoir de parler à la famille ou amis, respectivement. Des réponses narratives aux questions sur la fin de vie et la vie avec une maladie sont également décrites. Les résultats suggèrent que l'accent mis sur la gestion des symptômes, et le soutien des contacts sociaux, peut améliorer la santé des personnes âgées fragiles.
\end{abstract}

\begin{abstract}
We used a web-based mixed methods survey (HowsYourHealth - Frail) to explore the health of frail older (78\% age 80 or older) adults enrolled in a home-based primary care program in Vancouver, Canada. Sixty per cent of eligible respondents participated, representing over one quarter (92/350, 26.2\%) of all individuals receiving the service. Despite high levels of co-morbidity and functional dependence, 50 per cent rated their health as good, very good, or excellent. Adjusted odds ratios for positive self-rated health were $7.50,95$ per cent $C I[1.09,51.81]$ and $4.85,95$ per cent CI $[1.02,22.95]$ for absence of bothersome symptoms and being able to talk to family or friends respectively. Narrative responses to questions about end of life and living with illness are also described. Results suggest that greater focus on symptom management, and supporting social contact, may improve frail seniors' health.
\end{abstract}

1 Vancouver Coastal Health Research Institute Centre for Clinical Epidemiology \& Evaluation

2 Department of Family Practice, University of British Columbia

3 Centre for Health Services and Policy Research, University of British Columbia

4 School of Population \& Public Health, University of British Columbia

5 Department of Sociology, University of British Columbia

6 Department of Occupational Science \& Occupational Therapy, University of British Columbia

7 Community Engagement Advisory Network, Vancouver Coastal Health

8 Health Research Consultant, Balfour, British Columbia

* We gratefully acknowledge the following individuals: John H. Wasson (creator of HowsYourHealth survey tool, Emeritus Professor of Community and Family Medicine and Medicine, Dartmouth Medical School); Megan Luk and Asheya Kushner (research assistants) who administered the HowsYourHealth - Frail survey; Michelle Cox (research analyst, UBC Dept. of Family Practice Community Geriatrics) and Lisa Ronald (Vancouver Coastal Health Research Institute Centre for Clinical Epidemiology \& Evaluation) who assisted in data analysis; and the librarians of the BC College of Physicians and Surgeons Library who assisted with literature searches.

This study (2013-2014) was supported by a grant from the British Columbia College of Family Physicians and the Department of Family Practice Community Geriatrics.

Manuscript received: / manuscrit reçu : 23/11/15

Manuscript accepted: / manuscrit accepté : 20/12/16

Canadian Journal on Aging / La Revue canadienne du vieillissement 36 (3) : 273-285 (2017)

(c) Canadian Association on Gerontology 2017. This is an Open Access article, distributed under the terms of the Creative

Commons Attribution licence (http://creativecommons.org/licenses/by/4.0/), which permits unrestricted re-use,

distribution, and reproduction in any medium, provided the original work is properly cited. 
Mots clés : vieillissment, autoévaluation de santé, qualité de vie, personnes âgées fragiles et confinés chez soi, fin de vie

Keywords: aging, patient-reported outcome measures (PROMS), self-rated health, quality of life (QoL), homebound frail seniors, end of life

Correspondence and requests for reprints should be sent to / La correspondance et les demandes de tirés-à-part doivent être adresées à :

Margaret J. McGregor, M.D., M.H.Sc.

Department of Family Practice

University of British Columbia

Room 713, 828 West 10th Avenue

Vancouver, BC V5Z 1L8

(mrgret@mail.ubc.ca)

Frailty is a "multidimensional syndrome of loss of reserves (energy, physical, ability, cognition, health) that gives rise to vulnerability" (Rockwood et al., 2005, p. 489). One quarter of seniors aged 85 and older report moderate, severe, or total limitation in activities of daily living (Canadian Institute for Health Information, 2011). The most common of these limitations were not being able to bath or shower $(15 \%)$, walk $(11 \%)$, or use the washroom $(10 \%)$ without help (Canadian Institute for Health Information, 2011). The prevalence of frailty increases with age, with the weighted average prevalence of frailty among seniors aged 85 and older ranging from 22 per cent to 30 per cent (Collard, Boter, Schoevers, \& Oude Voshaar, 2012). Since the number of seniors in this age group is expected to dramatically increase over the next two decades (Jagger et al., 2011), we will see a consequent rise in the number of frail seniors in our communities.

Frailty, far more than age, predicts poor prognosis (Cacciatore et al., 2005), limited lifespan (Fried et al., 2001), a higher rate of surgical complications (Bickel, Gradinger, Kochs, \& Forstl, 2008; Fukuse, Satoda, Hijiya, \& Fujinaga, 2005), longer hospital stays (Keller, Bankwitz, Nobel, \& Delaney, 2014), and a greater risk of delirium and institutionalization (Bickel et al., 2008). Despite this evidence, health care for frail seniors often involves inappropriately aggressive acute care at the time of an acute health crisis (Sloan, 2009). The consequences of this may be harmful to the recipient of these services (Gillick, Serrell, \& Gillick, 1982) and the health care system more generally (Mallery \& Moorhouse, 2011). Furthermore, the opportunity cost of such interventions may be the failure to meet other needs of frail seniors (Cohen \& Franko, 2015). Moreover, the evidence demonstrates that health priorities change as lifespan becomes more limited (Gawande, 2014), and when adequately informed about the prognosis for advanced frailty, the interventions we offer may not be what frail people want (Mallery \& Moorhouse, 2011).

Health systems and providers nonetheless still struggle to understand how to meet the needs of this population. The term "patient-centred" is frequently invoked in policy documents discussing improved system design strategies for seniors (British Columbia Ministry of Health, 2015; Ontario Ministry of Health and Long-Term Care, 2012). With a growing senior population experiencing frailty and requiring increasing levels of community and hospital resources, there is intense interest in understanding how to recognize and manage frailty so as to improve health outcomes and quality of life as well as to reduce future hospitalization and avoid or delay admission to a nursing home (Béland \& Hollander, 2011; Canadian Frailty Network, n.d.). There is also a growing voice from seniors who are frail, demanding a more holistic and coordinated approach to their treatment (Canadian Frailty Network, n.d.). It is important to understand the perspectives of frail elderly patients accessing community-based services so that the services provided are responsive to the person's needs and context, supporting increased acceptance and utilization of services crucial for their well-being and independence (Themessl-Huber, Hubbard, \& Munro, 2007). However, there is relatively little research on self-reported experience (e.g., Patient Reported Experience Measures or PREMS) and outcomes (e.g., Patient Reported Outcome Measures or PROMS) of health in frail older people.

This study describes the results of a web-based survey (HowsYourHealth - Frail) (Nelson et al., 2015) administered to a sample of frail homebound seniors living in Vancouver, Canada, who were receiving home-based primary care as a result of their inability to access usual primary care due to frailty. The survey explored their perceived health and health care needs, experience, and outcomes. The survey tool was chosen for a number of reasons. First, at the time of the study, the provincial Ministry of Health and the physicians' association (The General Practice Services Committee of the BC Medical Association) were piloting a version of the Hows YourHealth survey with a view to its widespread use among ambulatory patient populations (British Columbia Ministry of Health, 2011; Wasson et al., 2012). We wished to align our research with this effort so as not to overburden clinicians with multiple tools. Second, the web-based tool was able to electronically generate a health report that participants could share 
with their formal and informal care providers. Third, the collected aggregate anonymized data were made available in real time to providers and program managers to inform them about common issues for clients. These design features were felt to have substantial potential clinical usefulness, the results of which will be analysed and described separately. Finally, the survey included two narrative questions, thereby offering a mixed methods approach to understanding "what frail people want".

Two prior studies have collected self-reported health measures on recipients of home-based primary care programs. Both were based in the United States and were part of randomized controlled trials to assess the overall effectiveness of these programs (Counsell et al., 2007; Hughes et al., 2000) and were restricted to quantitative measures of health-related quality of life. The Counsell et al. (2007) study was on a population considerably different from ours (younger population with substantial financial hardship). To our knowledge, no prior studies have used a mixed methods survey to explore self-reported health of seniors who are homebound as a result of advanced frailty. Given the known influence of context on self-reported health (Bobak, Pikhart, Hertzman, Rose, \& Marmot, 1998) and the limitations of solely using quantitative surveys in capturing the "patient voice" (Garces et al., 2012), our study therefore aimed to use a mixed methods approach to gain new insights into the self-reported health of homebound frail seniors in a Canadian setting. We describe the quantitative and qualitative responses to the survey and explore the association of selected survey responses with self-reported good general health.

\section{Methods}

\section{Study Population}

In 2008, a program of Home Visits for Vancouver Elders, called Home ViVE (HV), was established as part of a suite of community-based programs for frail older adults offered by the Vancouver health region (Vancouver Coastal Health Authority). The HV program serves approximately 350 frail elderly people in Vancouver, British Columbia (Rosenberg \& Slater, 2009). HV aims to provide comprehensive multidisciplinary longitudinal primary care to frail elderly adults who could otherwise not access ambulatory primary care due to functional physical and/or cognitive impairment.

The study population was a sample of HV patients who agreed to complete the survey and who met the following inclusion criteria: the absence of advanced dementia; no difficulty communicating in English; absence of uncontrolled substance use; and absence of mental health issues judged by the patient's primary care provider (family physician or nurse practitioner) to be a significant barrier to survey administration. Providers in the HV program were asked to identify patients that met the inclusion criteria, and these patients were invited to participate in the survey. The study received approval by the relevant Institutional Ethics Boards.

\section{Survey Content}

The "HowsYourHealth" survey instrument has been in existence since 1994 and accessible on the internet, for no charge, since 1997. It has been used in the United States and elsewhere to provide patient-reported validated quality measures among patients in multiple ambulatory settings (Nelson et al., 2015). Because of the marked differences in health status among frail versus non-frail individuals, a version for participants who are frail was developed in 2004 and was last revised in 2010.

The survey instrument contains questions about health conditions, physical and emotional symptoms, function, quality of life, experience of health care, and advance care planning. "Old age" is used in the survey as a plainlanguage term for self-defined "frailty". "Bothersome symptoms" is defined as "symptoms that were often or always bothersome during the past week," and include (a) trouble sleeping; (b) trouble eating; (c) trouble breathing; (d) stomach problems or feeling sick; (e) dizziness or weakness; (f) trouble with bowels including constipation; and (g) trouble urinating or wetting (1997-2016 FNX Corporation and Trustees of Dartmouth College, n.d.).

A number of the questions are "branched" so that if a respondent answers positively to the presence of a given symptom or need, they are asked a further question about provider awareness and/or support for the stated need or problem. The functional health measures have undergone reliability evaluation and crossvalidation testing with other measures and have been found to be both reliable and valid (Nelson, Landgraf, Hays, Wasson, \& Kirk, 1990). The other items have been in use for several decades, with minor modifications having been made on the basis of input from clinicians and patients (Nelson et al., 2015).

Embedded in the survey are also two opportunities for respondents to provide narrative answers. These are as follows: "If you knew you were going to die soon what would you do or say?" and "What do you hope for as you live with your illnesses?" Details of the questionnaire are available online (FNX Corporation and Trustees of Dartmouth College, n.d.). As part of our research, we also added customized questions related to the frequency of emergency room visits and hospital admissions over the past year. 


\section{Survey Administration}

Surveys were administered between June 2013 and July 2014 to eligible patients registered with the HV program. These individuals were sent an introductory letter followed by a phone call from a research assistant, who arranged an appointment time for survey completion with those who consented to participate.

Although the survey is web-based and can be selfadministered, we anticipated that many in this population would find it difficult to complete independently. Therefore, we hired three research assistants and equipped them with tablet devices to interview participants in their homes. In cases where patients wished to complete the survey independently, the research assistant would set them up on the tablet device and stay in the room to respond to any difficulties or questions. Given the advanced age and frailty of the population, in most cases, respondents opted to have the research assistant read out the questions to them and check off the appropriate response on their behalf. Survey respondents were also given an opportunity to ask an informal caregiver or family member to assist with responses and/or have this person complete the survey.

At the end of the survey, a plain language health summary of the patient's responses was printed from a mobile printer for the respondent to retain and/or share with their informal caregivers. Survey respondents were further given the option of asking the research assistant to upload a summary of their survey results to their electronic medical record for their primary care provider to review. In the course of survey administration, depending on self-identified need for more information, research assistants also provided interviewees with copies of relevant material on the following topics: advance care planning (British Columbia Ministry of Health, 2013), effective communication with health care providers (National Transitions of Care Coalition, n.d.), and self-care for patients and caregivers (19972016 FNX Corporation and Trustees of Dartmouth College, n.d.). Aggregate quantitative and qualitative data were available to the HV program's medical director to share with service providers and researchers online through the Dartmouth College secure server.

\section{Data Analysis}

We produced descriptive quantitative data of survey results. The percentages were calculated on the original denominator, including the missing data. We conducted subsequent tests of comparison to explore the association of selected patient factors with a self-report of general good health (defined as a composite variable reporting general health as good, very good, or excellent). All variables with a significance at $p<.020$ in bivariate analysis were entered into a multivariable logistic regression model $(n=80)$. The model fit was assessed by looking at the deviance/degrees of freedom (DF) to assess for over- or under-dispersion. If there was evidence of dispersion, we corrected using adjusted standard errors to improve the model fit. This is a more conservative approach, which increases the standard errors (width of the confidence intervals). Responses to branched questions were not included in the regression analysis because of their altered denominators. Data were analysed using SAS version 9.3 software (SAS Institute Inc., Cary, NC).

The analysis of qualitative data was completed by four researchers who started with open coding of the data and identifying information that seemed important and interesting (MacPherson \& McKie, 2010). These researchers first reviewed all the open-ended responses independently, each developing codes and coding the responses. Next, one of the researchers grouped the open codes into categories that spanned the individual examples and using an iterative process (Merriam, 2009); these categories and coding were compared and revised by the other three researchers. The categories created by the four researchers were then combined into themes.

\section{Results}

Of the 350 patients enrolled in HV, 153 were identified by their usual family doctor as appropriate for inclusion in the study and invited to participate. The primary reason for exclusion was the prevalence of advanced dementia, followed by difficulty communicating in English. Between June 2013 and July 2014, 92 individuals took part in the survey representing 60.1 per cent of eligible respondents and just over one quarter (92/350, 26.3\%) of all HV patients. In almost all cases, a research assistant entered the survey questions and responses, and patients themselves answered the questions with only 2 per cent $(n=7)$ opting to have an informal caregiver respond on their behalf. Missing data for each variable are reported in the tables. Among the close-ended questions, the number of missing data ranged from zero to 12 (e.g., there were 12 missing responses to the question asking the respondent if they were able to talk to family or friends). There were 37 missing responses to the open-ended question regarding what seniors hoped for as they lived with their illness, and 26 missing responses to the openended question regarding what seniors would do if they knew they were going to die soon.

\section{Demographic, Functional Characteristics and Provider Responsiveness}

Approximately three quarters of survey respondents were female $(n=68)$, and similarly, three quarters were age 80 or older $(n=69)$. Eighty-four per cent $(n=77)$ 
reported difficulty with at least one or more instrumental activity of daily living, and more than one half $(n=48)$ required assistance with personal care. Over one third $(n=32)$ were living in supportive or assisted living housing that provided meals, housekeeping, laundry services, and/or limited personal care services. A small number $(n=11)$ reported financial hardship or not being able to get the help or assistance they need (see Table 1).

\section{Medical Conditions, Physical Symptoms, Acute Health Services Use, and Provider Responsiveness}

Over three quarters of respondents reported having one or more serious conditions $(n=71,77.2 \%)$. Frailty (or "old age") was the most commonly self-reported serious condition $(n=38)$, followed by "memory trouble or Alzheimer's" $(n=19)$, heart disease $(n=18)$, and lung disease $(n=18)$ (see Table 1$)$. Of those reporting a serious condition, less than one third $(n=24)$ reported that they had been told the right amount about what to expect with their condition.

Just under three quarters of participants $(n=68)$ reported one or more bothersome symptoms in the last week (see Table 1 ). The most common symptoms were aching back or joints $(n=37)$, hearing trouble $(n=26)$, and trouble sleeping $(n=24)$. One third $(n=21)$ reported that their symptoms had been treated with substantial improvement ("problems much better"). Nearly half of the respondents used five or more medications daily $(n=44)$, and only 4 respondents said that most of their medications were used to treat pain.

Forty-two per cent $(n=39)$ had visited a hospital emergency department one or more times over the past 12 months, and 29 per cent $(n=27)$ had been admitted to the hospital one or more times over this time period (see Table 1).

\section{Self-Rated Quality of Health, Quality of Life, and Confidence in Self-Management}

Half of the respondents described their health as good, very good, or excellent ( $n=46)$ (see Table 2$)$. Similarly, over half $(n=50)$ reported their quality of life as "very good" or "pretty good". Less than 40 per cent $(n=36)$ reported they could manage all their symptoms. Over half $(n=48)$ said they could talk to family or friends all or most of the time. Just under half $(n=41)$ of respondents reported receiving the help they needed over the past week (see Table 2).

Tests of comparison for various characteristics were run on a composite variable of self-reported good general health (all those reporting general health as good, very good, or excellent). A significant and positive association was found between good general health and quality of life ( $p=.0001)$, ability to manage all symptoms $(p=.024)$, and being able to talk to family or friends $(p=.010)$. A similar association was found between good general health and the absence of one or more serious condition $(p=.006)$, bothersome symptom $(p=.001)$, or a visit to the hospital emergency department over the past 12 months $(p=.008)$. Age, not being told the right amount of information about a serious health condition, and needing help with personal care were unrelated to self-reported good general health (see Table 3).

The variables independently associated with positive overall health at $p<.020$ were entered into a multivariable logistic regression model (see Table 4). Quality of life was excluded due to the high degree of co-linearity of this variable with self-reported positive health. The variable no serious conditions lost its significance $(p=.156)$ in the multivariable logistic regression and was removed from the model. No visits to the hospital emergency department over the past year retained borderline significance $(p=.032)$, However, there was evidence of overdispersion in the model, and, therefore, we adjusted standard errors to improve the fit. After adjusting the standard error for the no visits to the hospital emergency department over the past year variable, the confidence interval widened considerably, $O R=3.13,95 \%$ CI [0.86, 11.40], $p=.084$, and therefore we dropped it from the final model. The final multivariable logistic regression model included no bothersome symptoms, OR 7.50, 95\% CI $[1.09,51.81], p=.041$; and able to talk to family or friends, OR 4.85, 95\% CI [1.02, 22.95], $p=.047$.

\section{End-of-Life Concerns among HowsYourHealth Survey Respondents}

When participants were asked about their fears or concerns at this stage in their life, the most common responses were fear of being a burden $(n=23,25.0 \%)$, financial concerns $(n=18,19.6 \%)$, losing control $(n=16$, $17.4 \%)$, and pain $(n=16,17.4 \%)$. Over half reported religion as a source of comfort (see Table 5).

Over two thirds ( $n=67,72.8 \%$ ) identified a family member as the decision maker if they were unable to make decisions. Although three quarters of participants $(n=71)$ felt that their designee knew what medical treatment they wanted if they became too sick to speak for themselves, only one quarter $(n=24)$ reported having their treatment wishes in writing.

The most common themes emerging from the analysis of the narrative responses to the question, "If you knew you would die soon, what would you like to do or say?" ( $n=68)$, included "giving," "spending time with family and/or friends," "saying goodbye," and "quality of death." Fifteen respondents reported that there was "nothing" they would say or do. A list of the identified themes and example quotes are described in Table 6. 
Table 1: Demographics, functional characteristics, medical conditions, physical symptoms, and reported acute health services use among HowsYourHealth Survey respondents

\begin{tabular}{|c|c|c|}
\hline Variable & $(n=92)$ & $\%$ \\
\hline Female & 68 & 73.9 \\
\hline \multicolumn{3}{|l|}{ Age } \\
\hline $50-69$ & 6 & 6.5 \\
\hline $70-79$ & 17 & 18.5 \\
\hline $80+$ & 69 & 75.0 \\
\hline \multicolumn{3}{|l|}{ Limited in an IADL (of 5 possible) ${ }^{a}$} \\
\hline Yes & 77 & 83.7 \\
\hline No & 13 & 14.1 \\
\hline Missing response ${ }^{b}$ & 2 & 2.2 \\
\hline \multicolumn{3}{|l|}{ Most common IADL limitation (of 5 possible)c } \\
\hline Handling money & 65 & 70.7 \\
\hline Missing response & 3 & 3.3 \\
\hline Meal preparation & 49 & 53.3 \\
\hline Missing response & 3 & 3.3 \\
\hline Travelling to places out of walking distance & 36 & 39.1 \\
\hline Missing response & 3 & 3.3 \\
\hline \multicolumn{3}{|l|}{ Needs help with personal care ${ }^{d}$} \\
\hline Yes & 48 & 52.2 \\
\hline No & 40 & 43.5 \\
\hline Missing response & 4 & 4.3 \\
\hline \multicolumn{3}{|l|}{ In an assisted living environment } \\
\hline Yes & 32 & 34.8 \\
\hline No & 51 & 55.4 \\
\hline Missing response & 9 & 9.8 \\
\hline \multicolumn{3}{|l|}{ Not have enough money for everyday needs } \\
\hline Yes & 11 & 12.0 \\
\hline No & 75 & 81.5 \\
\hline Missing response & 6 & 6.5 \\
\hline \multicolumn{3}{|l|}{ Help available if needed/wanted } \\
\hline A little or not at all & 7 & 7.6 \\
\hline Some / Quite a bit / As much as wanted & 82 & 89.1 \\
\hline Missing response & 3 & 3.3 \\
\hline 1 or more serious conditions (of 10 possible ${ }^{e}$ ) & 71 & 77.2 \\
\hline \multicolumn{3}{|l|}{ Serious condition complaints } \\
\hline "Old age" & 38 & 41.3 \\
\hline Memory trouble or Alzheimer's & 19 & 20.7 \\
\hline Heart disease or hardening of arteries & 18 & 19.6 \\
\hline Breathing trouble or lung disease & 18 & 19.6 \\
\hline Stroke, Brain or nerve disease & 16 & 17.4 \\
\hline Cancer & 7 & 7.6 \\
\hline Kidney trouble & 4 & 4.3 \\
\hline Live trouble & 0 & 0.0 \\
\hline HIV AIDS & 0 & 0.0 \\
\hline Other serious illness & 22 & 23.9 \\
\hline \multirow{2}{*}{\multicolumn{3}{|c|}{$\begin{array}{l}\text { If serious condition, told the right amount about } \\
\text { what to expect }\end{array}$}} \\
\hline & & \\
\hline Yes & 24 & 26.1 \\
\hline No & 38 & 41.3 \\
\hline No serious condition & 21 & 22.8 \\
\hline Missing response & 9 & 9.8 \\
\hline \multicolumn{3}{|l|}{1 or more bothersome symptoms (of 15 possible) f,g } \\
\hline Yes & 68 & 73.9 \\
\hline No & 22 & 23.9 \\
\hline Missing response & 2 & 2.2 \\
\hline \multicolumn{3}{|l|}{ Use 5 or more medications daily } \\
\hline Yes & 44 & 47.8 \\
\hline No & 44 & 47.8 \\
\hline Missing response & 4 & 4.3 \\
\hline
\end{tabular}

Continued
Table 1. Continued

\begin{tabular}{lrr}
\hline Variable & $(\boldsymbol{n}=\mathbf{9 2})$ & $\%$ \\
\hline Most medications are used to treat pain & & \\
(vs. some/none) & 4 & \\
Yes & 76 & 82.6 \\
No & 12 & 13.0 \\
Missing response & & \\
Number of times visited ED in past 12 months & 48 & 52.2 \\
None & 25 & 27.2 \\
1 visit & 14 & 15.2 \\
2 or more visits & 5 & 5.4 \\
Missing response & & \\
Number of times admitted to hospital in past & & \\
12 months & 59 & 64.1 \\
None & 17 & 18.5 \\
1 admission & 10 & 10.9 \\
2 or more admissions & 6 & 6.5 \\
Missing response & \\
\hline
\end{tabular}

a "Sometimes" and "no" category responses combined.

b "Missing response" means that a question(s) was skipped or not answered in the survey.

c Limited in IADL (Instrumental Activities of Daily Living) includes the following: travelling to places out of walking distance; shopping for groceries/clothes; meal preparation; doing housework; handling money without help.

d Needs help with personal care includes needing help with: eating, bathing, dressing or getting around the house.

e Serious conditions include the following: cancer; breathing trouble or lung disease; stroke, brain or nerve disease; liver trouble; kidney trouble; heart disease or hardening of the arteries; memory trouble or Alzheimer's disease; "Old Age"; HIV/AIDS; other serious illness.

f Symptoms that were often or always bothersome during the past week: trouble sleeping; trouble eating; trouble breathing; stomach problems or feeling sick; dizziness or weakness; trouble with bowels including constipation; trouble urinating or wetting. I

g The mean (SD) number of bothersome symptoms $(n=90)$, was $2.5(2.5)$, and the median $(I Q R)$ was $2.0(3.0)$.

In response to the question, "What do you hope for as you live with your illnesses?" ( $n=57)$, "getting better" and "maintaining current level of health" emerged as the predominant themes. Thirteen respondents made comments suggesting that they hope for "psychological health". The need for tangible, emotional, social, or financial "support" was also identified (see Table 6).

\section{Discussion}

This survey provides a cross-sectional look at qualitative and quantitative patient-reported experiences and outcomes of care in a sample of 92 homebound frail elderly individuals in Vancouver, Canada. All respondents were receiving home-based primary care due to their inability to access usual care as a result of frailty, advanced chronic disease, and/or disability. Although prior studies have examined health characteristics of 
Table 2: Self-rated health, quality of life, and confidence in self-management among HowsYourHealth Survey respondents

\begin{tabular}{|c|c|c|}
\hline Variable & $(n=92)$ & $\%$ \\
\hline $\begin{array}{l}\text { Overall health fair or poor (vs. excellent/ } \\
\text { very good/good) }\end{array}$ & 46 & 50.0 \\
\hline \multicolumn{3}{|l|}{ Overall health } \\
\hline Poor & 14 & 15.2 \\
\hline Fair & 32 & 34.8 \\
\hline Good & 29 & 31.5 \\
\hline Very good & 13 & 14.1 \\
\hline Excellent & 4 & 4.3 \\
\hline \multicolumn{3}{|l|}{ Quality of life } \\
\hline Very bad/pretty bad & 16 & 17.4 \\
\hline Good and bad about equal & 24 & 26.1 \\
\hline Pretty good/very good & 50 & 54.3 \\
\hline Missing response & 2 & 2.2 \\
\hline \multicolumn{3}{|l|}{ Can manage all symptoms } \\
\hline Yes & 36 & 39.1 \\
\hline No & 46 & 50.0 \\
\hline Missing response & 10 & 10.9 \\
\hline \multicolumn{3}{|l|}{ Able to talk to family or friends } \\
\hline All the time & 30 & 32.6 \\
\hline Most of the time & 18 & 19.6 \\
\hline Some of the time & 20 & 21.7 \\
\hline A little of the time & 6 & 6.5 \\
\hline None of the time & 6 & 6.5 \\
\hline Missing response & 12 & 13.0 \\
\hline \multicolumn{3}{|l|}{ Received needed help in past week } \\
\hline Yes & 41 & 44.6 \\
\hline No & 46 & 50.0 \\
\hline Missing response & 5 & 5.4 \\
\hline \multicolumn{3}{|l|}{ Anticipates could get a month's help } \\
\hline Yes & 66 & 71.7 \\
\hline No & 22 & 23.9 \\
\hline Missing response & 4 & 4.3 \\
\hline
\end{tabular}

similar populations (Jagger et al., 2011), this is one of relatively few studies that describes patient-reported experiences and outcomes of care by frail seniors who are homebound as a result of advanced frailty.

One interesting finding is that the frequency of medical conditions identified through self-report appears to be less than the calculated frequency of the same conditions derived from clinical and administrative data sources. For example, despite the advanced age of the population and the fact that all respondents had difficulty accessing usual primary care as a criterion for receipt of the HV service, less than half (41.3\%) identified "old age" (frailty) as a serious condition. Similarly, the frequency of self-reported heart and lung disease (19.6\%) is at the low end of previously reported frequencies derived from clinical data sources (range $=$ $18.6 \%$ to $40.6 \%$ for heart disease and $18.4 \%$ to $34.9 \%$ for lung disease) in similar populations receiving homebased primary care (Beck, Arizmendi, Purnell, Fultz, \& Callahan, 2009; Chang, Jackson, Bullman, \& Cobbs, 2009; De Jonge, Taler, \& Boling, 2009; Rosenberg, 2012; Wajnberg, Wang, Aniff, \& Kunins, 2010).
Likewise, only one in five respondents (20.7\%) reported "memory problems or Alzheimer's" as a serious condition, which is substantially lower than the dementia prevalence rates ranging from 33.8 per cent to 64.5 per cent reported in studies on similar populations derived from clinical data (Beck et al., 2009; Chang et al., 2009; Ornstein, Hernandez, DeCherrie, \& Soriano, 2011; Rosenberg, 2012; Wajnberg et al., 2010). Self-reported dementia prevalence may in part be explained by our study exclusion criteria that screened out those with advanced dementia; however, combined with the lower self-reported prevalence rate of other chronic conditions, selection bias of respondents is unlikely to fully explain this under-reporting of dementia.

The prior literature on the correlation between selfreport and clinical diagnosis is mixed. In a U.S. study of community-dwelling disabled older women (aged 65 and older), kappa statistics analysis of self-report and physician diagnosis of diabetes mellitus, cancer, stroke, and disc disease was excellent, and increasing co-morbidity and age did not reduce the validity (Simpson et al., 2004). Other research has found that the correlation between self-report and clinician diagnosis declined with age older than 65 years, less education, and increasing co-morbidity (Okura, Urban, Mahoney, Jacobsen, \& Rodeheffer, 2004).

Beyond a possible underestimation of self-reported health conditions, one half of survey respondents in our study rated their health as good despite being unable to access usual ambulatory care as a result of advanced physical and/or mental disability. This is lower than rates of positive health reported in two surveys $(78 \%$ and $60 \%$ respectively) of English $(n=851)$ (Collerton et al., 2009) and Swedish $(n=650)$ (Nagga, Dong, Marcusson, Skoglund, \& Wressle, 2012) seniors aged 85 and older. However, those surveys were among community-dwelling seniors who were not self-selected for the level of frailty and disability represented in our sample. Prior research has described an attenuation of the inverse association of self-rated health and disability in very old age groups (Hoeymans, Feskens, Kromhout, \& van den Bos, 1997), and it is likely this previously described "optimism" of the very old is a factor in all these populations reporting good health despite substantial co-morbidity and frailty.

Unlike self-report of chronic conditions, self-reported annual emergency department visits and hospital admissions rates in our study $(42.4 \%, n=39$; and $29.4 \%, n=27$ respectively) appear fairly similar to rates reported from other sources (De Jonge et al., 2009). One Canadian study reported annual population emergency department visit rates of 41.7 per cent for those over age 85 (Doupe et al., 2008), and annual hospital admission rates for homebound U.S. seniors is reported to 
Table 3: Tests of comparison for select variables on self-rated health and overall health

\begin{tabular}{|c|c|c|c|c|c|}
\hline \multirow[b]{2}{*}{ Variable } & \multicolumn{2}{|c|}{$\begin{array}{l}\text { Health Rated as Good, } \\
\text { Very Good, or Excellent }\end{array}$} & \multicolumn{3}{|c|}{$\begin{array}{l}\text { Health Rated as } \\
\text { Fair or Poor }\end{array}$} \\
\hline & $(n=46)^{a}$ & $\%$ & $(n=46)^{b}$ & $\%$ & $\boldsymbol{p}$ \\
\hline Age $\geq 80$ years & 36 & 78.3 & 33 & 71.7 & .470 \\
\hline Female & 35 & 76.1 & 34 & 73.9 & .810 \\
\hline Not enough money for everyday needs & 3 & 6.5 & 8 & 17.4 & .195 \\
\hline Missing response & 1 & 2.2 & 3 & 6.5 & \\
\hline Help available if needed/ wanted $^{d}$ & 44 & 95.7 & 38 & 82.6 & .058 \\
\hline Missing response & 1 & 2.2 & 2 & 4.3 & \\
\hline One or more serious conditions $\mathrm{e}^{\mathrm{e}}$ & 30 & 65.2 & 41 & 89.1 & .006 \\
\hline Missing response & 0 & 0.0 & 0 & 0.0 & \\
\hline If serious condition, told the right amount about what to expect & 10 & 21.7 & 12 & 26.1 & .541 \\
\hline Missing response & 0 & 0.0 & 4 & 8.7 & \\
\hline One or more visits to the ED over past year & 14 & 30.4 & 25 & 54.3 & .008 \\
\hline Missing response & 1 & 2.2 & 4 & 8.7 & \\
\hline One or more hospital admissions over past year & 11 & 23.9 & 16 & 34.8 & 0.146 \\
\hline Missing response & 1 & 2.2 & 5 & 10.9 & \\
\hline Quality of life pretty good or very good & 39 & 84.8 & 11 & 23.9 & $<.0001$ \\
\hline Missing response & 1 & 2.2 & 1 & 2.2 & \\
\hline Can manage all symptoms & 23 & 50.0 & 12 & 26.1 & .024 \\
\hline Missing response & 4 & 8.7 & 6 & 13.0 & \\
\hline Able to talk to family or friends & 32 & 69.6 & 16 & 34.8 & .010 \\
\hline Missing response & 2 & 4.3 & 10 & 21.7 & \\
\hline Received help needed in the past week & 38 & 82.6 & 33 & 71.7 & .116 \\
\hline
\end{tabular}

a $(\operatorname{good}=29$; very good $=13$; excellent $=4)$

b (poor $=14$; fair $=32$ )

c "Needs help with personal care" includes needing help with eating, bathing, dressing, or getting around the house.

d Some, quite a bit, as much as wanted.

e Serious conditions include cancer; breathing trouble or lung disease; stroke, brain, or nerve disease; liver trouble; kidney trouble; heart disease or hardening of the arteries; memory trouble or Alzheimer's disease; "Old Age"; HIV/AIDS; other serious illness.

f Symptoms that were often or always bothersome during the past week: trouble sleeping; trouble eating; trouble breathing; stomach problems or feeling sick; dizziness or weakness; trouble with bowels including constipation; trouble urinating or wetting.

$g$ Limited in an IADL (Instrumental Activities of Daily Living) includes travelling to places out of walking distance; shopping for groceries/clothes; meal preparation; doing housework; handling money without help.

Note: Chi square or Fisher's exact test used for all tests of comparison on categorical variables. $t$-test used for all tests of comparison on continuous variables. ED = hospital Emergency Department; IADL = Independent Activities of Daily Living; $M=$ mean; $S D=$ standard deviation; $M d n=$ Median; $I Q R=$ interquartile range

range from 38.8 to 52.1 per cent (Ornstein et al., 2015). It should be noted that our study's rates do not factor in the participants' length of "exposure" to, or time receiving, the $\mathrm{HV}$ service, and the acute service use rates may, for new entrants to the program, reflect usage prior to program entry.
The strong association of self-reported good general health with quality of life and fewer serious conditions (Meng \& D'Arcy, 2015) is not surprising. These associations have been reported in other studies on frail elderly populations (Hoeymans et al., 1997) and are largely unmodifiable. However, both "the absence of bothersome 
Table 4: Logistic regression models for factors associated with positive overall health

\begin{tabular}{|c|c|c|c|c|}
\hline \multirow[b]{2}{*}{ Variable } & \multicolumn{2}{|c|}{ Unadjusted } & \multicolumn{2}{|c|}{ Adjusted $(n=80)$} \\
\hline & OR & $95 \% \mathrm{Cl}$ & OR & $95 \% \mathrm{Cl}$ \\
\hline No serious conditions ${ }^{a}$ & 4.37 & {$[1.44,13.26]$} & & \\
\hline No visits to ED over past year & 3.26 & {$[1.35,7.87]$} & & \\
\hline No bothersome symptoms ${ }^{b}$ & 6.43 & {$[1.96,21.05]$} & 7.50 & {$[1.09,51.81]$} \\
\hline Able to talk to family or friends & 3.33 & {$[1.31,8.48]$} & 4.85 & {$[1.02,22.95]$} \\
\hline
\end{tabular}

a Serious conditions include cancer; breathing trouble or lung disease; stroke, brain, or nerve disease; liver trouble; kidney trouble; heart disease or hardening of the arteries; memory trouble or Alzheimer's disease; "Old Age"; HIV/AIDS; other serious illness.

b Symptoms that were often or always bothersome during the past week: trouble sleeping; trouble eating; trouble breathing; stomach problems or feeling sick; dizziness or weakness; trouble with bowels including constipation; trouble urinating or wetting. Note: $\mathrm{OR}=$ odds ratio; $\mathrm{Cl}=$ confidence interval; $\mathrm{ED}=$ hospital Emergency Department

symptoms" and "the ability to talk to family or friends" are at least partially modifiable and therefore of relevance to the design of services for frail older adults.

Table 5: End-of-life concerns among HowsYourHealth Survey respondents

\begin{tabular}{|c|c|c|}
\hline Variable & $(n=92)$ & $\%$ \\
\hline \multicolumn{3}{|l|}{ Most common fears/ concerns ${ }^{a}$} \\
\hline Being a burden & 23 & 25.0 \\
\hline Financial issues & 18 & 19.6 \\
\hline Losing control & 16 & 17.4 \\
\hline Pain & 16 & 17.4 \\
\hline Family issues & 11 & 12.0 \\
\hline Not having enough help when I need it & 11 & 12.0 \\
\hline Getting medical care when I need it & 8 & 8.7 \\
\hline Fear, I am just afraid & 7 & 7.6 \\
\hline Legal issues & 7 & 7.6 \\
\hline Where I might die & 7 & 7.6 \\
\hline Who I will leave behind & 7 & 7.6 \\
\hline 911: When and when not to use it & 2 & 2.2 \\
\hline Sexual issues & 0 & 0.0 \\
\hline \multicolumn{3}{|l|}{$\begin{array}{l}\text { Religion (and/or God) is a source of strength } \\
\text { and comfort }\end{array}$} \\
\hline Not very much & 38 & 41.3 \\
\hline Somewhat & 20 & 21.7 \\
\hline A lot & 27 & 29.3 \\
\hline Missing response & 7 & 7.6 \\
\hline \multicolumn{3}{|l|}{$\begin{array}{l}\text { If too sick, who would decide about medical } \\
\text { treatment? }\end{array}$} \\
\hline Family & 67 & 72.8 \\
\hline Doctor & 35 & 38.0 \\
\hline Not Sure & 7 & 7.6 \\
\hline Friends & 5 & 5.4 \\
\hline Other & 1 & 1.1 \\
\hline \multicolumn{3}{|l|}{ Designee knows advance care plan } \\
\hline Yes & 71 & 77.2 \\
\hline No/I don't know & 12 & 13.0 \\
\hline Missing response & 9 & 9.8 \\
\hline \multicolumn{3}{|l|}{ Advance care plan in writing } \\
\hline Yes & 24 & 26.1 \\
\hline No/Not sure & 59 & 64.1 \\
\hline Missing response & 9 & 9.8 \\
\hline
\end{tabular}

Although the absence of bothersome symptoms remained a significant independent predictor of good general health in the adjusted model, the number of serious conditions did not. This suggests that a greater emphasis on symptom control may improve selfreported health in this population. Given these results, it is interesting to note the relatively low rate at which medication for pain was prescribed.

Our study found that twice the number of those reporting good general health reported an ability to talk to family or friends compared to those reporting poor health ( $n=32$ vs. $n=16$ respectively, $p=0.010$ ). This effect remained significant in the multivariable logistic regression model, OR 4.85, 95\% CI [1.02, 22.95]. The association of good social support from family and a strong network of friends with self-reported good general health has been previously described (Ashida \& Heaney, 2008; Victor \& Bowling, 2012; Zunzunegui et al., 2004), and social support measured by frequency of contact with network members has been associated with delay in the onset and progression of dementia (Crooks, Lubben, Petitti, Little, \& Chiu, 2008; Fratiglioni, Paillard-Borg, \& Winblad, 2004). Likewise, social engagement, measured by participation in social or productive activities, was found to be positively associated with lower levels of disability (Mendes de Leon, Glass, \& Berkman, 2003).

Improving social contact and reducing social isolation is a potentially modifiable factor with a potential to improve the general health of frail seniors. Our research suggests that policy decisions aimed at supporting informal social support systems show considerable promise in improving frail seniors' health. Furthermore, the research suggests that those who lack an informal network may benefit from formal social care, and that current policy restrictions of home support programs to personal care services only may be shortsighted. A failure to factor in the compelling evidence for social care and better self-reported health in service design for frail seniors may represent a missed opportunity for 
Table 6: Themes of HowsYourHealth Survey respondents' answers to questions: "If you knew you were going to die soon, what would you like to do or say?" and "What do you hope for as you live with your illnesses?"

\begin{tabular}{|c|c|c|}
\hline Coding Theme & $(n=92)$ & Example \\
\hline Giving & 20 & $\begin{array}{l}\text { ".. share what little money I have with people who need it. And if my } \\
\text { organs are good enough, give them away ..." }\end{array}$ \\
\hline Nothing to say or do & 15 & "Nothing. Can't think of anything ..." \\
\hline Spending time with friends and/or family & 11 & "Spend time with family." \\
\hline Saying goodbye & 11 & "Say goodbye to my friends." \\
\hline Gratitude & 7 & "Thank my son and some other people for the help they have given me." \\
\hline Avoidance & 4 & "Don't want to think about it." \\
\hline \multicolumn{3}{|c|}{ "What do you hope for as you live with your illnesses?"b } \\
\hline Getting better & 20 & $\begin{array}{l}\text { "That I can be more active ... get back to being able to get outside } \\
\text { and do some shopping on my own." }\end{array}$ \\
\hline Maintaining current level of health & 17 & "Not to get worse. To stay the way I am." \\
\hline Symptom management & 6 & "I hope that I experience no pain ..." \\
\hline Resignation & 5 & "This business of aging is beyond our control for the most part." \\
\hline Quality of death & 4 & "Dying in my sleep without a long protracted end." \\
\hline
\end{tabular}

a 68 participants provided responses, and a respondent's comment may have been coded with more than one theme; there were 26 missing or no responses for this question.

b 57 participants provided responses, and a respondent's comment may have been coded with more than one theme; there were 37 missing or no responses for this question.

prevention of costly downstream and potentially harmful acute services use (Sloan, 2009). The relationship of self-reported health and social support also highlights the multidimensional nature of health where previous research has found that disease co-morbidity explains only 11 per cent of the variance in self-rated health with 27 per cent being explained by other domains (Perruccio, Katz, \& Losina, 2012).

Less than one in 10 reported not being sure about who would make medical decisions, and over three quarters reported their designee knew what medical treatment they wanted if they became too sick to speak for themselves. Despite this, just over one quarter of respondents reported having what treatment they wanted in writing, and approximately two thirds were either unsure or reported no written plan. This frequency is substantially lower than that of written advance care plans reported from clinically derived data in similar services where completion of written advance directives ranges from 97.3 per cent to 100 per cent (Chang et al., 2009; De Jonge et al., 2014). However, advance care plans in these studies appear to refer to the presence of provider documentation of patients' request for full cardiopulmonary resuscitation in the event of an arrest (so-called "code" status), rather than documentation of values and preferences for lifeprolonging measures under a range of scenarios.
A strength of the survey was the multidimensional approach to end-of-life concerns providing both categorical and open-ended questions. Both ways of framing the question elicited different concerns. When asked for categorical responses about fears and concerns at the end of life, the most common response was "being a burden". When asked open-ended questions about "what you would do or say if you knew you were dying", the most common themes were related to actions of communicating with others, giving to informal caregivers, and leaving a legacy. In some respect, these responses may be seen as two ends of the same expression, with the latter being a form of recognition or gratitude to others for self-perceived burden. Pain emerged as an issue in both the survey and narrative responses, but was less frequently expressed in the latter.

One limitation of our study included the fact that, despite participants' frailty, they were all deemed to be capable of responding to our survey, and therefore the study excluded those with substantial dementia. The number of missing responses from participants is a second limitation. Factors that contributed to the missing responses included the heterogeneity (in terms of disease spectrum, functional capacity, first language, etc.) of the population surveyed, and the survey length (1.5 to 2 hours) resulting in respondent fatigue. 
A third limitation is the fact that those who were unable to understand English were excluded. Given the substantial proportion of Chinese and Punjabi speaking individuals residing in Vancouver, future efforts should be directed to measuring perceptions of health in these populations. Fourth, although the HowsYourHealth survey has been used and evaluated in ambulatory primary care settings (Nelson et al., 2015), the HowsYourHealth - Frail version has not been similarly evaluated. Nonetheless, relatively little quantitative or qualitative research exists on homebound elders regarding their perception of health and end of life at a time when the health care system is increasingly challenged to respond to the growing numbers of frail people living in our communities. Finally, confidence intervals for the regression analyses were wide due to the small sample size, resulting in a considerable possible range for the magnitude of effect.

It should also be noted that our unit of analysis was the individual patient, whereas in reality, virtually all of this population depends on their formal and informal caregivers for health and functional support. Future research on self-reported health in this group should aim to involve these individuals and explore the nature of key caregiver-patient relationships, as an essential feature of supporting care at home in this population.

\section{Conclusion}

One half of survey respondents in our sample rated their health as good, very good, or excellent, despite high levels of co-morbidity and functional dependence, suggesting that advanced age may mitigate the impact of disability and medical illness on self-reported good general health, consistent with prior research. The association of improved symptom control and social contact with self-reported good general health suggests that a stronger focus on these features in seniors' service delivery may have the potential to improve self-reported health. Finally, concerns about being a burden and a desire to communicate with family/friends and give thanks were common themes in the quantitative and qualitative survey questions about end of life.

\section{References}

Ashida, S., \& Heaney, C. A. (2008). Differential associations of social support and social connectedness with structural features of social networks and the health status of older adults. Journal of Aging and Health, 20(7), 872-893. doi: $10.1177 / 0898264308324626$

Beck, R. A., Arizmendi, A., Purnell, C., Fultz, B. A., \& Callahan, C. M. (2009). House calls for seniors: building and sustaining a model of care for homebound seniors. Journal of the American Geriatrics Society, 57, 1103-1109. doi:10.1111/j.1532-5415.2009.02278.x
Béland, F., \& Hollander, M. J. (2011). Integrated models of care delivery for the frail elderly: International perspectives. Gaceta Sanitaria, 25(Suppl. 2), 138-146. doi:10.1016/j. gaceta.2011.09.003

Bickel, H., Gradinger, R., Kochs, E., \& Forstl, H. (2008). High risk of cognitive and functional decline after postoperative delirium. A three-year prospective study. Dementia and Geriatric Cognitive Disorders, 26(1), 26-31. doi:10.1159/000140804

Bobak, M., Pikhart, H., Hertzman, C., Rose, R., \& Marmot, M. (1998). Socioeconomic factors, perceived control and self-reported health in Russia. A cross-sectional survey. Social Science and Medicine, 47(2), 269-279.

British Columbia Ministry of Health. (2011). Patients as Partners: Nothing about me without me! First Annual Report. Retrieved from http://www2.gov.bc.ca/assets/gov/ health/about-bc-s-health-care-system/primary-healthcare/patients-as-partners-annual-report-2011.pdf

British Columbia Ministry of Health. (2013). My Voice: Expressing My Wishes for Future Health Care Treatment. Advance Care Planning Guide. Retrieved from http:// www.health.gov.bc.ca/library/publications/year/2013/ MyVoice-AdvanceCarePlanningGuide.pdf

British Columbia Ministry of Health. (2015). Primary and Community Care in BC: A Strategic Policy Framework. Retrieved from http://www.health.gov.bc.ca/library/ publications / year/2015/primary-and-communitycare-policy-paper.pdf

Cacciatore, F., Abete, P., Mazzella, F., Viati, L., Della Morte, D., D'Ambrosio, D., ... Rengo, F. (2005). Frailty predicts long-term mortality in elderly subjects with chronic heart failure. European Journal of Clinical Investigation, 35(12), 723-730. doi:10.1111/j.1365-2362.2005.01572.x

Canadian Frailty Network. (n.d.). Frailty in Canada. Retrieved from http:/ / www.cfn-nce.ca/frailty-in-canada /

Canadian Institute for Health Information. (2011). Health Care in Canada, 2011: A focus on seniors and aging. Ottawa, ON: Author. Retrieved from https://secure.cihi.ca/free_ products/HCIC_2011_seniors_report_en.pdf

Chang, C., Jackson, S. S., Bullman, T. A., \& Cobbs, E. L. (2009). Impact of a home-based primary care program in an urban Veterans Affairs medical center. Journal of the American Medical Directors Association, 10(2), 133-137. doi:10.1016/j.jamda.2008.08.002

Cohen, M., \& Franko, J. (2015). Living up to the promise. Vancouver, BC: Integrated Care Advocacy Group and the BC Healthcare Coalition. Retrieved from http:/ / bchealthcoalition.ca / sites / default / files / uploads / Living \%20Up\%20To\%20The \%20Promise \%20-\%20 Full\%20Report \%20-\%20press\%20-\%20\%20new\%20 appendixA.pdf

Collard, R. M., Boter, H., Schoevers, R. A., \& Oude Voshaar, R. C. (2012). Prevalence of frailty in communitydwelling older persons: A systematic review. Journal 
of the American Geriatrics Society, 60(8), 1487-1492. doi:10.1111/j.1532-5415.2012.04054.x

Collerton, J., Davies, K., Jagger, C., Kingston, A., Bond, J., Eccles, M. P., ... Kirkwood, T. B. L. (2009). Health and disease in 85 year olds: Baseline findings from the Newcastle 85+ cohort study. BMJ, 339, b4904. doi:10.1136/bmj.b4904

FNX Corporation and Trustees of Dartmouth College. (n.d.). Hows YourHealth.org. Retrieved from https://veryill.org/

1997-2016 FNX Corporation and Trustees of Dartmouth College. (n.d.). Chapter 2: Common Problems and Important Solutions. Retrieved from https:/ / veryill.org/chapters/ chapter2.html

Counsell, S. R., Callahan, C. M., Clark, D. O., Tu, W., Buttar, A. B., Stump, T. E., \& Ricketts, G. D. (2007). Geriatric care management for low-income seniors: A randomized controlled trial. JAMA, 298(22), 2623-2633. doi:10.1001/ jama.298.22.2623

Crooks, V. C., Lubben, J., Petitti, D. B., Little, D., \& Chiu, V. (2008). Social network, cognitive function, and dementia incidence among elderly women. American Journal of Public Health , 98(7), 1221-1227. doi:10.2105/AJPH.2007.115923

De Jonge, K. E., Jamshed, N., Gilden, D., Kubisiak, J., Bruce, S. R., \& Taler, G. (2014). Effects of home-based primary care on Medicare costs in high-risk elders. Journal of the American Geriatrics Society, 62(10), 1825-1831. doi:10.1111/jgs.12974

De Jonge, K. E., Taler, G., \& Boling, P. A. (2009). Independence at home: Community-based care for older adults with severe chronic illness. Clinics in Geriatric Medicine, 25(1), 155-169. doi:10.1016/j.cger.2008.11.004

Doupe, M., Kozyrskyj, A., Soodeen, R. A., Derksen, S., Burchill, C., \& Huq, S. (2008). An initial analysis of emergency departments and urgent care in Winnipeg. Winnipeg, MB: Manitoba Centre for Health Policy. Retrieved from http:/ / mchp-appserv.cpe.umanitoba.ca/reference/EDFull.pdf

Fratiglioni, L., Paillard-Borg, S., \& Winblad, B. (2004). An active and socially integrated lifestyle in late life might protect against dementia. The Lancet. Neurology, 3(6), 343-353. doi:10.1016/S1474-4422(04)00767-7

Fried, L. P., Tangen, C. M., Walston, J., Newman, A. B., Hirsch, C., Gottdiener, J., et al. (2001). Frailty in older adults: evidence for a phenotype. The Journals of Gerontology. Series A, Biological Sciences and Medical Sciences, 56(3), M146-M156.

Fukuse, T., Satoda, N., Hijiya, K., \& Fujinaga, T. (2005). Importance of a comprehensive geriatric assessment in prediction of complications following thoracic surgery in elderly patients. Chest, 127(3), 886-891. doi:10.1378/ chest.127.3.886

Garces, J. P. D., Prutsky Lopez, G. J., Wang, Z., Elraiyah, T. A., Nabhan, M., Brito Campana, J. P., ... Murad, M. H. (2012). Eliciting patient perspective in patient-centered outcomes research: A meta narrative systematic review. Washington, DC: Patient-Centered Outcomes Research Institute. Retrieved from http:/ / www.pcori.org/assets / Eliciting-PatientPerspective-in-Patient-Centered-Outcomes-Research-AMeta-Narrative-Systematic-Review1.pdf

Gawande, A. (2014). Being Mortal: Medicine and What Matters in the End. New York, NY: Metropolitan Books, Henry Holt.

Gillick, M. R., Serrell, N. A., \& Gillick, L. S. (1982). Adverse consequences of hospitalization in the elderly. Social Science \& Medicine, 16(10), 1033-1038.

Hoeymans, N., Feskens, E. J., Kromhout, D., \& van den Bos, G. A. (1997). Ageing and the relationship between functional status and self-rated health in elderly men. Social Science E Medicine, 45(10), 1527-1536.

Hughes, S. L., Weaver, F. M., Giobbie-Hurder, A., Manheim, L., Henderson, W., Kubal, J. D., ... Cummings, J. (2000). Effectiveness of team-managed home-based primary care: A randomized multicenter trial. JAMA, 284(22), 2877-2885.

Jagger, C., Collerton, J. C., Davies, K., Kingston, A., Robinson, L. A., Eccles, M. P, ... Bond, J. (2011). Capability and dependency in the Newcastle $85+$ cohort study. Projections of future care needs. BMC Geriatrics, 11, 21. doi:10.1186/1471-2318-11-21

Keller, D. S., Bankwitz, B., Nobel, T., \& Delaney, C. P. (2014). Using frailty to predict who will fail early discharge after laparoscopic colorectal surgery with an established recovery pathway. Diseases of the Colon and Rectum, 57(3), 337-342. doi:10.1097/01.dcr.0000442661.76345.f5

MacPherson, I., \& McKie, L. (2010). Qualitative research in programme evaluation. In I. Bourgeault, R. Dingwall, \& R. De Vries (Eds.), The SAGE handbook on qualitative methods in health research (pp. 454-478). London, ENG: Sage.

Mallery, L. H., \& Moorhouse, P. (2011). Respecting frailty. Journal of Medical Ethics, 37(2), 126-128. doi:10.1136/ jme.2010.040147

Mendes de Leon, C. F., Glass, T. A., \& Berkman, L. F. (2003). Social engagement and disability in a community population of older adults: The New Haven EPESE. American Journal of Epidemiology, 157(7), 633-642. doi:10.1093/aje/ kwg028

Meng, X., \& D'Arcy, C. (2016). Determinants of self-rated health among Canadian seniors over time: A longitudinal population-based study. Social Indicators Research, 126(3), 1343-1353. doi:10.1007/s11205-015-0941-6

Merriam, S. B. (2009). Qualitative Research: A Guide to Design and Implementation. San Francisco, CA: Jossey-Bass.

Nagga, K., Dong, H. J., Marcusson, J., Skoglund, S. O., \& Wressle, E. (2012). Health-related factors associated with hospitalization for old people: Comparisons of elderly aged 85 in a population cohort study. Archives of Gerontology and Geriatrics, 54(2), 391-397. doi:10.1016/j. archger.2011.04.023 
National Transitions of Care Coalition. (n.d.). Taking care of MY health care. Retrieved from http://www.ntocc. org/Portals/0/PDF/Resources/Taking_Care_of_My_ Health_Care.pdf

Nelson, E. C., Eftimovska, E., Lind, C., Hager, A., Wasson, J. H., \& Lindblad, S. (2015). Patient reported outcome measures in practice. BMJ, 350, g7818. doi:10.1136/ bmj.g7818

Nelson, E. C., Landgraf, J. M., Hays, R. D., Wasson, J. H., \& Kirk, J. W. (1990). The functional status of patients: How can it be measured in physicians' offices? Medical Care, 28(12), 1111-1126.

Okura, Y., Urban, L. H., Mahoney, D. W., Jacobsen, S. J., \& Rodeheffer, R. J. (2004). Agreement between self-report questionnaires and medical record data was substantial for diabetes, hypertension, myocardial infarction and stroke but not for heart failure. Journal of Clinical Epidemiology, 57(10), 1096-1103. doi:10.1016/j.jclinepi. 2004.04.005

Ontario Ministry of Health and Long-Term Care. (2012). Ontario's action plan for health care: Better patient care through better value from our health care dollars. Toronto, ON: Government of Ontario. Retrieved from http:// www.health.gov.on.ca/en/ms/ecfa/healthy_change/ docs/rep_healthychange.pdf

Ornstein, K. A., Leff, B., Covinsky, K. E., Ritchie, C. S., Federman, A. D., Roberts L., ... Szanton, S. L. (2015). Epidemiology of the Homebound Population in the United States. JAMA 175(7), 1180-1186. doi:10.1001/ jamainternmed.2015.1849

Ornstein, K., Hernandez, C. R., DeCherrie, L. V., \& Soriano, T. A. (2011). The Mount Sinai (New York) Visiting Doctors Program: Meeting the needs of the urban homebound population. Care Management Journals, 12(4), 159-163. doi:10.1891/1521-0987.12.4.159

Perruccio, A. V., Katz, J. N., \& Losina, E. (2012). Health burden in chronic disease: Multimorbidity is associated with self-rated health more than medical comorbidity alone. Journal of Clinical Epidemiology, 65(1), 100-106. doi:10.1016/j.jclinepi.2011.04.013

Rockwood, K., Song, X., MacKnight, C., Bergman, H., Hogan, D. B., McDowell, I., \& Mitnitski, A. (2005). A global clinical measure of fitness and frailty in elderly people. Canadian Medical Association Journal, 173(5), 489-495. doi:10.1503/cmaj.050051

Rosenberg, T., \& Slater, J. (2009). A home care practice that works. Retrieved from http:/ /www.slideshare.net/BCAGCP/ a-home-care-practice-that-works-for-syllabus

Rosenberg, T. (2012). Acute hospital use, nursing home placement, and mortality in a frail community-dwelling cohort managed with Primary Integrated Interdisciplinary Elder Care at Home. Journal of the American Geriatrics Society, 60(7), 1340-1346. doi:10.1111/j.15325415.2012.03965.x

Simpson, C. F., Boyd, C. M., Carlson, M. C., Griswold, M. E., Guralnik, J. M., \& Fried, L. P. (2004). Agreement between self-report of disease diagnoses and medical record validation in disabled older women: Factors that modify agreement. Journal of the American Geriatrics Society, 52(1), 123-127. doi:10.1111/j.1532-5415.2004.52021.x

Sloan, J. (2009). A bitter pill-How the medical system is failing the frail elderly. Vancouver, BC: Greystone Books.

Themessl-Huber, M., Hubbard, G., \& Munro, P. (2007), Frail older people's experiences and use of health and social care services. Journal of Nursing Management, 15(2), 222-229. doi:10.1111/j.1365-2834.2007.00726.x

Victor, C. R., \& Bowling, A. (2012). A longitudinal analysis of loneliness among older people in Great Britain. The Journal of Psychology, 146(3), 313-331. doi:10.1080/0022 3980.2011.609572

Wajnberg, A., Wang, K. H., Aniff, M., \& Kunins, H. V. (2010). Hospitalizations and skilled nursing facility admissions before and after the implementation of a home-based primary care program. Journal of the American Geriatrics Society, 58(6), 1144-1147. doi:10.1111/j.1532-5415. 2010.02859.x

Wasson, J. H., Forsberg, H. H., Lindblad, S., Mazowita, G., McQuillen, K., \& Nelson, E. C. (2012). The medium is the (health) measure: Patient engagement using personal technologies. Journal of Ambulatory Care Management, 35(2), 109-117. doi:10.1097/JAC.0b013e31824a235e

Zunzunegui, M. V., Kone, A., Johri, M., Beland, F., Wolfson, C., \& Bergman, H. (2004). Social networks and self-rated health in two French-speaking Canadian community dwelling populations over 65. Social Science \& Medicine, 58(10), 2069-2081. doi:10.1016/j.socscimed.2003.08.005 